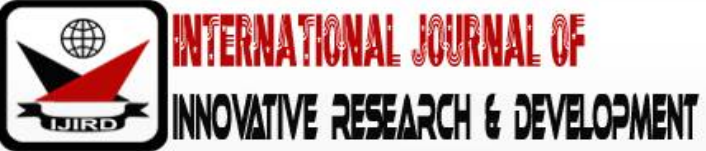

ISSN 2278 - 0211 (Online)

\section{Effect of Personalised Instruction on Students' Learning Outcomes and Attitude in mathematics Education at Senior Secondary School, Lagos State, Nigeria}

\author{
Alabi, Ibraheem Abiola \\ Lecturer, Department of Mathematics, Adeniran Ogunsanya \\ College of Education (AOCOED), Oto/ Ijanikin, Lagos State, Nigeria
}

\begin{abstract}
:
This study examined the effect of personalised instruction on students' learning outcomes and attitude in mathematics education at senior secondary school, Lagos State, Nigeria of quasi-experimental design of two non-equivalent groups with sample comprised 177 students from two public secondary schools. Two research instruments were used, achievement test and questionnaire with reliabilities coefficients of 0.84 and 0.78 respectively. The data were analysed using both descriptive statistics (mean, standard deviation and bar chart) and inferential statistics (T-Test and ANCOVA) which were used for research questions and in testing the hypotheses at 0.05 level of significance respectively. The finding revealed positive effect of personalised instruction on students over non-personalised students and male over female also when considering in terms of gender on attitude. Furthermore, H01, [t=0.93; $p>0.05]$ is not rejected; H02, pretest value of $F(1,176)=131.214 ; p<0.05$; posttest value of $F(1,176)=30.998$; $p<$ 0.05 is rejected; H03, gender value of $F(1,176)=0.005 ; p>0.05$ is not rejected; and H04, interaction value of $F(1,176)$ $=1.362 ; p>0.05$ is not rejected. Conclusively, personalised instruction on students has positive effect towards students learning outcomes and attitude in mathematics classroom.
\end{abstract}

Keywords: Personalised instruction, Attitudes, Questionnaire, Mathematics, Learning Outcomes

\section{Introduction}

Mathematics is a compulsory and inevitable subject in secondary school curriculum that occupies a conspicuous position among the branches of knowledge in any educational institution. It is the mainstay to all sciences subjects in school, playing a prominent role in the revitalization of nations and peoples, towards the progress, growth and prosperity of earlier civilizations, as well as the current era (Farrajallah, 2017). In building a nation rightfully among other developed nations, needs to focus on mathematics, science and technology are very essential (Akudo, Olaoye, Alabi \& Otun, 2017). In spite of mathematics greatness and importance, mathematics education suffers from apparent deficiencies in teaching and learning instruction as the students' attitude towards mathematics remain a great challenge for the educators.

Obaid (2004) indicates a feeling of dissatisfaction for mathematics poor instruction towards learning, in which mathematics education suffer difficulties in the content, teaching and learning instruction, educational activities, and outcomes learning at all stages of education. As a matter fact, mathematics requires a planned learning instruction that would allow students' active participation in mathematics classroom such as personalisation of instruction in mathematics. To facilitate participation of students, personalization, an instructional-design has been made to allow learners to convert textual information to familiar referents (Akinsola \& Awofala, 2009). Bates and Wiest (2004) opined that personalization increases motivation of learners in mathematics classroom. This was also supported by Cakir and Simsek (2010) that see personalisation of instruction as tools for learning that affects student achievement positively.

Even though, when a required teaching instruction is applied, students' attitude still pose a major constraint for students learning outcomes. However, many researchers have found out that factors influence the students' learning outcomes in mathematics are numerous in which student attitudes make the headline among others. Bohner \& Wänke, (2002) defined attitudes as a summary evaluation of an object of thought towards an action. Awofala, Arigbabu \& Awofala (2013), revealed that school syllabus has immense effect on learning outcome. Many studies have revealed serious problem while learning mathematics (Tahar, Ismail, Zamani \& Adnan, 2010; Tezer \& Karasel, 2010; Tapia \& Marsh, 2004, Mubeen, Saheed \& Arif, 2013). Importance of personalized instruction for students' have been focused in many studies. Group personalization has been found to have a positive effect in a study conducted by Ku \& Sullivan (2002) on 136 fourth grade Taiwanese students and their teachers. Both students and teachers using personalized problems showed better attitudes toward the programme compared to those who are not using it. Familiarity (reduced cognitive load) and interest have been found two most important factors providing greater success. 350 senior secondary school year one Nigerian 
students-based study by Awofala (2014) revealed that personalised instruction students had higher levels of selfconfidence, liking, usefulness, and motivation but recorded low level of anxiety regarding mathematics word problems compared with the non-personalised group students. Another study had been conducted by Akinsola \& Awofala (2009), revealed that 320 senior secondary students in Nigeria, had shown significant different results due to the use of personalized print-based instruction and gender difference. However, this paper focused on the effect of personalised instruction on students' attitude and learning outcomes in logarithmic expression problems in mathematics. Importantly, every nation desire includes a better development that would improve the standard of education at all level. Thus, developing students by finding solution to their attitude and learning outcomes in mathematics become imperative and forms an essential part of the core of this paper.

\section{Statement of the Problem}

Olosunde and Olaleye (2010) remarked on the failure rate of students' outcomes in mathematics examinations that has been on the increase side nationally ranging from 2001 to 2006. Meanwhile, in the recent year, according to Chief Examiner of West African Examination Council, WAEC (2017) reported that 2017 is better than 2016 yet not encouraging at all. This means something has to be done to avert the problem from getting worse subsequently, otherwise Nigeria future generation would find it difficult to curb in particular towards education enhancement.

Importantly, logarithmic expression problems in mathematics is identified as one of the mathematics concepts which pose difficulties to students in peripheral examinations. According to the report of WAEC (2017) of Chief Examiner for Mathematics (Core), finding the value of a logarithmic expression was among the weaknesses of candidates as difficulty and that most students avoid answering questions on logarithmic expression or arbitrarily attempt them in examinations. This show that the learning outcomes of students in mathematics become worrisome in every year. Students with a negative disposition towards learning mathematics would not be able to apply and find the basic of the logarithmic expression. It is with the intention of the researcher to profound solution to finding the value of a logarithmic expression through means of personalization of instruction on students' learning outcomes and attitudes in mathematics.

\section{Purpose of the Study}

The purpose of the study was to investigate the effect of personalised instruction on students' learning outcomes and attitude in mathematics education at senior secondary school in mathematics. In explicit terms, the study sought to explore:

- $\quad$ Stance toward mathematics between experimental and control groups students for mathematics.

- $\quad$ Outcome of mathematics learning between experimental and control groups students.

- Stance toward mathematics between experimental and control groups students for mathematics arising due to gender.

- Outcome of mathematics learning between experimental and control groups students arising due to gender. how learning outcomes is getting affected due to the interaction effect of methods and gender in experimental and control groups.

\subsection{Null hypotheses}

The confidence interval has been set at $95 \%$.

- $\quad \mathrm{H}_{01}$ : students' learning attitude from experimental group does not create any significant difference with the learning attitude of students from control group.

- $\mathrm{H}_{02}$ : students' learning outcome from experimental group does not create any significant difference with the learning outcome of students from control group.

- $\mathrm{H}_{03}$ : students' learning outcome from experimental group does not create any significant difference with the learning outcome of students from control group because of gender difference.

- $\mathrm{H}_{04}$ : students' learning outcome from experimental group does not create any significant difference with the learning outcome of students from control group because of interaction effect of methods and gender.

\section{Methodology}

The study employed a quasi-experimental design which involved two non-equivalent groups. The sample comprised 177 Senior Secondary Two (SSII) students (91 males \& 86 females) from two public secondary schools in Lagos State. There was no randomization of subjects as intact classes were randomly assigned to experimental and control groups. School A comprising of 94 students (48 males \& 46 females) served as the experimental group while school B comprising of 83 students (43 males \& 40 females) served as the control group. Two research instruments were used which include, achievement test and questionnaire.

On achievement test, a pre-test is used to measure students' fundamental knowledge in mathematics and further compared the result with post-test score which were assigned after the treatment. The data were collected using Achievement Test on logarithmic expression which comprised 20 items. The items were presented in a multiple-choice format with four alternative choices with one correct answer. The contests which was basically on concepts and principles of logarithmic expression was strengthened in content validity and reliability by three professional mathematics educators. Its reliability was tested on 20 students who did not participate in the study and a Cronbach Reliability Coefficient of 0.84 was obtained.

The questionnaire was designed by the researcher for the purpose of getting information on students' learning attitude towards mathematics, to sought for personal information of the respondents in terms of sex of twenty-five 
questions. Four Likert Scale was used with option of - Strongly Agree, Agree, Disagree and Strongly Disagree. The questionnaire was validated by some experts in the field of research. Cronbach Alpha method was used to determine the reliability of the items and a reliability coefficient of 0.78 was obtained. The data collected were analysed in the consideration of the research questions and hypothesis. In analyzing the data, both descriptive statistics (mean, standard deviation and bar chart) and inferential statistics. In testing the hypothesis formulated, the t-test and ANCOVA analysis were used and it were tested at $5 \%$ level of significance.

\section{Results}

To deal with this research question one, responses of the respondents to the questionnaire items were summarized in both experimental and control groups. The mean scores in respect of the results of each item was computed. Figure 1 give the summary of these results.

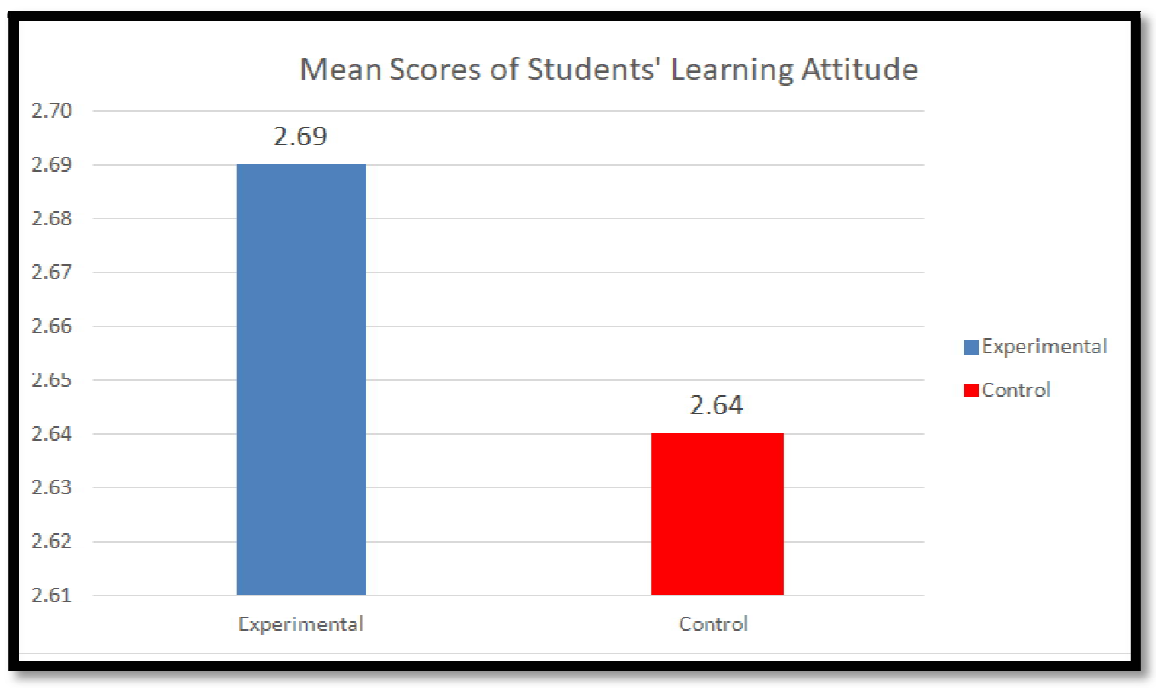

Figure 1: Mean Scores of Students' Learning Attitude

From the results presented in fig. 1, it was shown that the mean scores of students' learning attitude in experimental group is 2.69 while in control group is 2.64 . This indicated that students' learning attitude mean score of experimental groups is higher than mean score of control group.

\subsection{Research Question Two}

The question asked that to what extent is the gender difference of students' attitude in the experimental and control groups? To deal with this question, responses of the respondents to the questionnaire items were summarized in terms of gender for both experimental and control groups. The mean scores in respect of the results of each item was computed. Figure 2 gives the summary of these results.

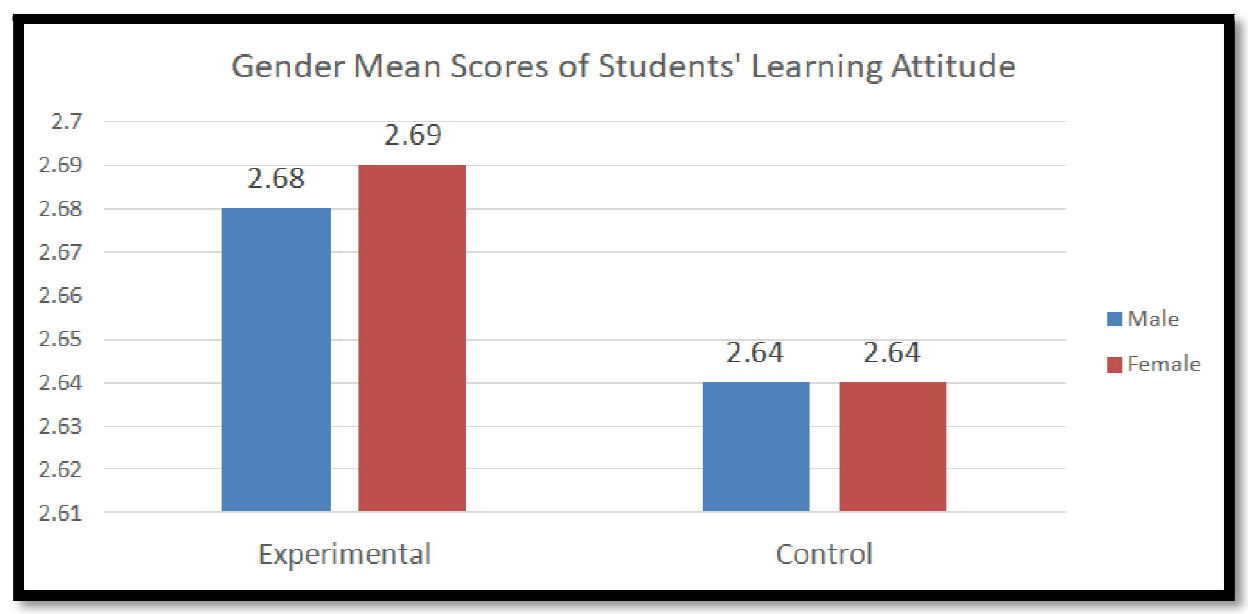

Figure 2: Gender Mean Scores of Students' Learning Attitude

From the results presented in fig. 2, it was shown that the male mean scores of students' learning attitude in experimental group is 2.68 while in control group is 2.64 and female mean scores of students' learning attitude in experimental group is 2.69 while in control group is 2.64. This indicated that male mean scores of students' learning attitude of experimental is higher than male mean score of control group. Similarly, female mean scores of students' learning attitude of experimental is higher than female mean score of control group. 


\subsubsection{Hypothesis One}

There is no statistical significant difference of students' learning attitude in the experimental and control groups.

\begin{tabular}{|c|c|c|c|c|c|c|c|c|}
\hline & Groups & N & Mean & Std. Deviation & df & t value & P value & Decision \\
\hline \multirow{2}{*}{ Experimental } & 94 & 2.69 & 0.33 & 175 & 0.93 & 0.49 & Not Significant \\
\cline { 2 - 8 } & Control & 83 & 2.64 & 0.31 & & & & \\
\hline
\end{tabular}

Table 1: T-Test Analysis on Students' Learning Attitude in Experimental and Control $[T=0.93 ; P>0.05]$

The result in the t-test table shows that there is no statistical significant difference of students' learning attitude in the experimental and control groups. [t=0.93; $\mathrm{p}>0.05]$. Therefore, $\mathrm{H}_{01}$ is not rejected.

\begin{tabular}{|c|c|c|c|c|c|}
\hline Source & $\begin{array}{c}\text { Type III Sum of } \\
\text { Squares }\end{array}$ & df & Mean Square & F & Sig. \\
\hline Corrected Model & $995.348^{a}$ & 4 & 248.837 & 63.356 & 0.000 \\
\hline Intercept & 66.489 & 1 & 66.489 & 16.929 & 0.000 \\
\hline Pretest & 515.354 & 1 & 515.354 & 131.214 & 0.000 \\
\hline Gender & 0.19 & 1 & 0.19 & 0.005 & 0.944 \\
\hline Groups & 121.746 & 1 & 121.746 & 30.998 & 0.000 \\
\hline Gender ${ }^{*}$ Groups & 5.350 & 1 & 5.350 & 1.362 & 0.245 \\
\hline Error & 675.545 & 172 & 3.928 & & \\
\hline Total & 25437.000 & 177 & & & \\
\hline Corrected Total & 1670.893 & 176 & & & \\
\hline
\end{tabular}

Table 2: Analysis of Covariance (ANCOVA) of Students' Learning Outcomes in

Experimental and Control Groups

a. $\quad R$ Squared $=.596$ (Adjusted $R$ Squared $=.586$ )

\subsubsection{Hypothesis Two}

Statistical significant difference of students' learning outcomes in the experimental and control groups has been shown in Table 2 that pretest value of $F(1,176)=131.214 ; p<0.05$ is significant at 0.000 while the posttest value $F(1,176)$ $=30.998 ; \mathrm{p}<0.05$ is also significant at 0.000 . Therefore, $\mathrm{H}_{\mathrm{o} 2}$ is rejected .

\subsubsection{Hypothesis Three}

Table 2 shows no statistical significant gender difference of students' learning outcomes in the experimental and control groups with value of $F(1,176)=0.005$; $p>0.05$ which is not significant at 0.944 . Therefore, $\mathrm{H}_{03}$ is not rejected.

\subsubsection{Hypothesis Four}

There is no statistical significant interaction effect of methods and gender on students' learning outcomes in the experimental and control groups. The result shows that there is no statistical significant interaction effect of methods and gender on students' learning outcomes in the experimental and control groups from Table 2 that interaction value of $F(1$, 176) $=1.362 ; \mathrm{p}>0.05$ which is not significant at 0.245 . Therefore, $\mathrm{H}_{04}$ is not rejected.

\section{Discussion of findings}

The findings revealed that the mean score of students' learning attitude of experimental group is higher than those in control group and also when considering in terms of gender, the mean scores of male and female students' of experimental group are higher than those in control group which is in support to Ku \& Sullivan (2002) that group personalization having a positive impact on attitudes as both students and teachers using personalized problems showed better attitudes toward the programme than those using non-personalized word problems. The results further revealed that hypothesis one indicating that there is no statistical significant difference of students' learning attitude in the experimental and control groups which is in contrary to Ku \& Sullivan (2002) findings who discovered that personalized instruction as implicated to reduce cognitive load while interest are the major factors that lead to greater success solving personalized versus non-personalized problems.

Hypothesis two indicating that there is a significant difference between the students' learning outcomes in the experimental and control groups which is in support to Akinsola \& Awofala (2009) findings that there exist significant differences in the mathematics in word problem achievement and self-efficacy beliefs of personalized and nonpersonalized groups.

In contradiction to Akinsola and Awofala (2009) findings, students' learning outcome from experimental group does not create any significant difference with the learning outcome of students from control group because of gender difference. Hypothesis four indicates that students' learning outcome from experimental group does not create any significant difference with the learning outcome of students from control group because of interaction effect of methods and gender. 


\section{Conclusion}

The study was carried out to investigate the effect of personalised instruction on students' learning outcomes and attitude in mathematics education at senior secondary school, Lagos State, Nigeria. Considering the results of this study, it easy to conclude that personalised instruction on students in mathematics classroom will effect positively their learning outcomes and also change the students attitude towards learning mathematics.

\section{Recommendations}

The following recommendations are made based on the findings:

- Personalised instruction to students should be encoraged at senior secondary schools as its implicated to their learning outcomes.

- Teacher ought to understand students interest towards what form of instruction to be personalised that would produce require result.

- The establishment of personalised instrution as training centre should be encouraged so as to give the use of personalised instruction wide coverage.

- Pre-service teacher should be trained to understand personalized instruction as they are future teacher to teach future students.

\section{References}

i. Akinsola, M. K. \& Awofala, A. O. A. (2009). Effect of Personalization of Instruction on Students' Achievement and Self-efficacy in Mathematics Word Problems. International Journal of Mathematical Education in Science and Technology, 40(3), 389-404.

ii. Akudo, O. K., Olaoye, A. A., Alabi, I. A. \& Otun I. W. (2017) Tiered instruction and students achievements for mathematical growth and sustainable development ABACUS, Journal of Mathematical Association of Nigeria (MAN) Vol. 42, No 2. Pp. 242.

iii. Awofala, A. O. A. (2017) effect of personalisation of instruction on students' anxiety in mathematical word problems in Nigeria. Bulgarian Journal of Science and Education Policy (BJSEP), Volume 11, Number 1,

iv. Awofala, A. O.A. (2014). Examining personalisation of instruction, attitudes toward and achievement in mathematics word problems among Nigerian senior secondary school students. International Journal of Education in Mathematics, Science and Technology, 2(4), 273-288.

v. Awofala, A. O. A., Arigbabu, A. A. \& Awofala, A. A. (2013). Effects of framing and team individualized instructional strategies on senior secondary school students' attitudes toward mathematics. Acta Didactica Naponcensia, 6(1), $1-22$.

vi. Awofala, A. O. A., Balogun, T. A. \& Olagunju, M. A. (2011). Effects of three modes of personalization on students' achievement in mathematics word problems in Nigeria. International Journal for Mathematics Teaching and Learning (Online) Available, http://www.cimt.plymouth.ac.uk/journal/awofala.pdf

vii. Bates, E. T., Wiest, L. R. (2004). Impact of personalization of mathematical word problems on student performance. The Mathematics Educator, 14(2), 17-26.

viii. Bohner, G., \& Wänke, M. (2002). Attitudes and attitude change. Psychology Press.

ix. Cakir, O., Simsek, N. (2010), A comparative analysis of the effects of computer and paper-Based personalization on student achievement, Computers \& Education 55. pp. 1524-1531

x. Dhlamini, J., \& Mogari, D. (2013). The effect of a group approach on the performance of high school mathematics learners. Pythagoras, 34(2), Art. \#198, 9 pages. http://dx.doi. org/10.4102/pythagoras. v34i2.198.

xi. Farrajallah, A. E. (2017) The Impact of Employing the (Think - Pair - Share) Strategy to Gain

xii. Some Number Sense Skills and Mathematical Communication Skills Among Fifth Grade Students.

xiii. Ku, H-Y. \& Sullivan, H. J. (2002). Student Performance and Attitudes Using Personalised

xiv. Mathematics Instruction. Educational Technology Research and Development, 50(1), 21-33.

xv. Mohamed, L. \& Waheed, H. (2011). Secondary Students' Attitude towards Mathematics in a

xvi. Selected School of Maldives. International Journal of Humanities and Social Science Vol. 1 No. 15, pp.277-281

xvii. Mubeen S., Saheed S. \& Arif, M. H. (2013) Attitude towards mathematics and academic achievement in mathematics among secondary level Boys and Girls. IOSR Journal of Humanities and Social Science (JHSS), Volume 6, Issue 4, pp 38 - 41

xviii. Obaid, William Taodhars. (2004). Mathematics education for all children in the light of the requirements of the standards and the culture of thinking, Oman, Dar Al-Masira.

xix. Olosunde, G.R. \& Olaleye, O.0. (2010). Effect of concept mapping strategy on senior secondary school students' performance in mathematics. Journal of National Mathematical Sciences, 1 (1), 29-53.

xx. Renninger, K. A., Ewen, L., \& Lassher, A. K (2002). Individual interest as context in expository text and mathematical word problems. Learning and Instruction, 12, 467-491

xxi. Tahar, N. F., Ismail, Z., Zamani, N. D., \& Adnan, N. (2010). Students" Attitude Toward

xxii. Mathematics: The Use of Factor Analysis in Determining the Criteria. Procedia-Social and Behavioral Sciences, 8, 476-481.

xxiii. Tezer, M. \& Karasel, N. (2010). Attitudes of primary school 2nd and 3rd grade students towards mathematics course. Procedia Social and Behavioural Sciences, 2, 5808-5812

xxiv. WAEC, (2017). West African examinations council chief examiners' reports. Yaba: Lagos. 